\title{
Photo-graphy
}

Marianna Michałowska

\section{The Art of the Document: Photography and Trauma ${ }^{1}$}

DO|:70.18318/td.2015.en.2.5

$\mathrm{f}$ we look at artistic representations on the subject of the Holocaust, we will see that contemporary artists, the generation born after the Shoah, are focused on discovering their own path to its remembrance. It also becomes clear that realizations are frequently based on memory as a source of images of a past which the artist has no direct experience of. Thus, the task of representing the Holocaust requires above all a definition of one's attitude to documents of the past. These are, on the one hand, narrations of survivors passed on to successive generations, and on the other, visual messages - photographs and films - preserved in the archives. Typically, facts from the past are authenticated in the popular consciousness by these technical images. Persuaded that a still or motion camera registers things objectively and without involvement, ${ }^{2}$ we assume the resultant photographs to be the basis of reliable reports on reality. But can they re-

1 Extended version of a text presented in Polish during "Memory of the Shoah - Contemporary Representations, " a conference that took place in Łódź in May 2003.

2 Susan Sontag says: "photography is actually an act of non-intervention," cf. Susan Sontag, o fotografii, trans. Sławomir Magala (Warszawa: WAiF, 1986), 16 .

\section{Marianna}

Michałowska is

a professor at the

Adam Mickiewicz

University in Poznań, and an employee of the Institute of Cultural Studies at AMU. She conducts research on the visual sphere of contemporary artistic culture (photography, urban studies). In her critical texts she engages problems associated with the media, and is an author of projects which employ photography and also a curator of exhibitions. She publishes her works in scholarly periodicals and artistic publications. She is the author of the following books: Niepewność przedstawienia. Od kamery.obskury do wspótczesnej fotografi (2004). obrazutajony. Szkice o fotografii i pamiec (2007), Foto-teksty. Zwiqzki fotografi z narracja (2012). 
ally be considered as reports, if they don't show "everything" - the complete background of events? The non-involvement of the photographer also turns out to be equivocal.

In the case of photographs which serve as a basis for knowledge about the Holocaust, we are faced with the incomparability of available sources. Who actually took the pictures? The oppressors or the victims? The latter are represented by scraps of testimony from before the Holocaust - mostly scenes of everyday life that were swept away by the establishment and eventual liquidation of the ghettos. By contrast, photographs that filled the archives of the Reich showed the days when the industry of death was in full swing. And there are also the archives of the Allies (e.g. the shocking photographic report by an American, Margaret Bourke-White). How are we to deal with these documents today?

\section{The Document - Empty Space}

In the context defined above, Dariusz Jabłoński's Fotoamator (Photoamateur) is, in many respects, an intriguing case. A few hundred slides found in 1987 in a Vienna antiquarian shop gave rise to a documentary on the everyday life of the ghetto in Eodź. ${ }^{3}$ In the film, the author juxtaposes black and white images of contemporary Łódź with colour slides taken from 1940-41 by Walter Genewein, an accountant at the ghetto in Eódź (Getto Litzmanstadt), and he confronts Genewein's story with that told by Arnold Mostowicz, a survivor from the ghetto. Both the ethical aspects of Genewein's work, who skillfully photographed the smoothly operating machine into which the Ghetto had been transformed (more specifically, in the years 1940-1941), and his comments accompanying the images have already been analysed repeatedly. Equally interesting as the ethical aspect is the written correspondence quoted in the film, between the photographer and AGFA, a company. Analyses of these communications emphasise the banality of evil. Even the director of the documentary himself stresses that he became interested in "the story of a man in an extreme situation," someone who agreed to be a cog in the machine. Engaged in work, says Jabłoński, we fail to notice what or whom we serve.4

In this article, I would like to focus on yet another aspect of Jabłoński's film. Upon closer inspection, we will recognize it as a film about two ways

3 It is not the first film in which Genewein's material has been used. According to some authors, Alan Adelson made a documentary entitled Łodz Ghetto in the 1990 s.

Tadeusz Szyma, "Dokument skorygowany," Kino, 10 (1998): 7; lan Strękowski, "Kilka Wątpliwości," http://www.republika.pl/fotoamator 
of recording the past: a film documentary made about a photographic document. The issue put forward is that of the documentary nature of photography, that still and silent image. "The principal problem with the artistic processing of the Genewein's slides in the film," writes Tadeusz Szyma, expressing his doubts about the photographs used in Fotoamator, "was this correction of a highly specific document, falsified for all its realism, giving the effect not only of truth about the Holocaust, but also heightening, in term of both expression and drama, its impact on the viewer." 5 The use of photography in a film generates problems other than a formal one, and it is not just the issue of translating one medium into another. Except for the photochemical medium, photography and film have little in common. Hence, the issue is not just the fact that photographs can serve merely as "footage" for a film, but that the photographic image and its "falsifying" nature, to use Szyma's term, need to be corrected. What then should this correction involve?

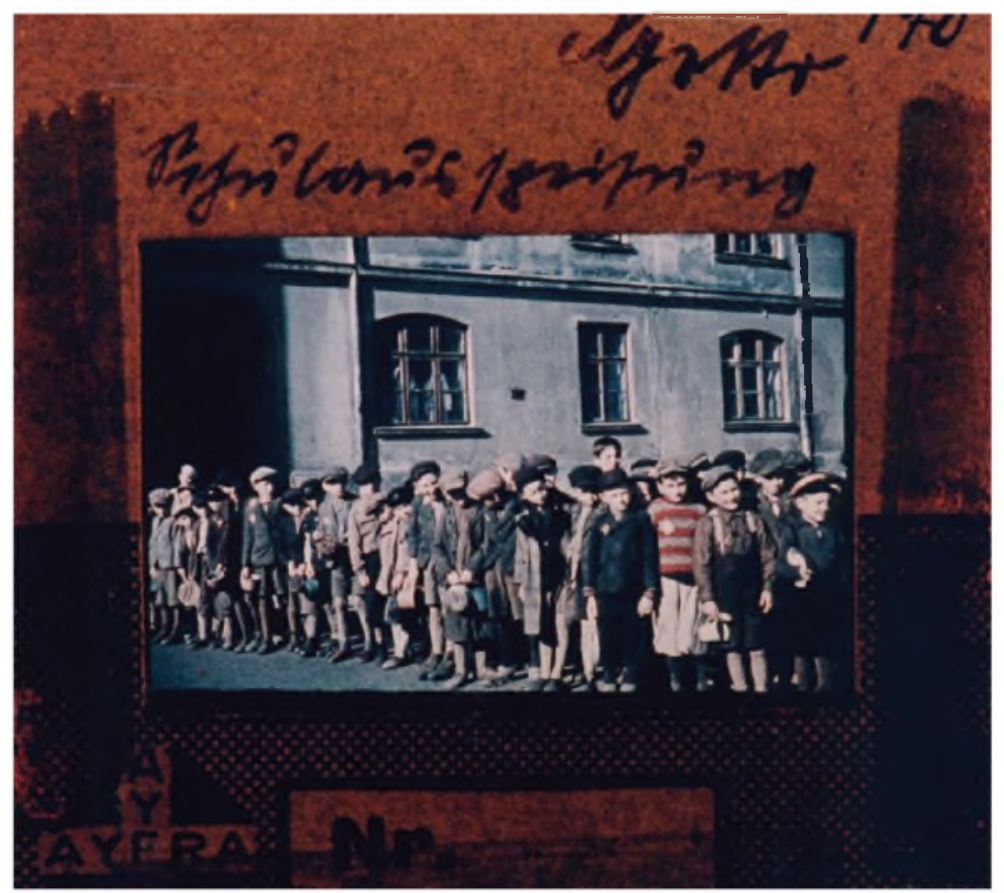

A frame by Walter Genewein used in Dariusz Jablonski's film Fotoamator [Photoamateur], database Filmpolski.pl, http./Www.filmpolski.pl/fp/index.php?galeria_filmu=459238 (accessed 2016-10-o6)

5 Szyma, "Dokument skorygowany," 7 . 
The point is that a colourful picture of the ghetto in no way resembles other archival images of the ghettos that we know. And the images of the Holocaust that appear in our minds are also in black and white, not in colour. The contemporary manner of filming feature movies about WWII in black and white confirms this mode of perception of images of the past (Schindler's List, to mention only one of the biggest film productions of recent years). While historical archives and popular films could suffice to explain this black-and-white perception of the past in people born after 1945, what should be taken to account for the shock Genewein's slides caused in people who survived those times?

At some point in the film, Mostowicz comments concerning the slides that "it's not what is in my memories." Indeed, colours tend to fade from the visual archives of individual memory, and on the other hand, it is impossible to render the memory of the Holocaust separate from an image of death. There is no death on Genewein's sildes. What is depicted is the life of "a small Jewish town inside a city." Paradoxically, the shock caused by Genewein's colour slides does not result from the horror of the picture, but from its banality. The slides are realistic and strangely ordinary. Deprived of the usually contaminated black-and-white surface mediating the image, they look astonishingly contemporary. Evil and tragedy are hidden deep below the surface. We are aware of them only because we know what happened to the Ghetto. The photographs show nothing of the events to come.

Why are we not able to predict from the pictures what is soon to happen? Why can we not sense their hidden content? Let us refer to the semiotics of photography. In his Rhetoric of the Image Roland Barthes concludes that the meaning of photographic images goes beyond the denoted iconic message. ${ }^{6}$ True, the photograph is "anchored" in connotation (determined by objective references undoubtedly), but the referential "anchorage" does not forejudge the image's meaning. "In order to re ad his last (or first) level of image, all that is needed is knowledge bound up with our perception."7 Photography leads itself to interpretation only owing to this "almost anthropological knowledge." ${ }^{8}$ Therefore, photographs intended to communicate a given meaning are accompanied by some kind of commentary. Even if the commentary is not spoken out loud, the photograph is still described in some way. But what happens, if we do not have such knowledge? We see objects, people, events, but we cannot say what they are essentially a part of.

6 Roland Barthes, "Rhetoric of the Image," in Classic Essays on Photography, ed. Alan Trachtenberg (New Haven: Leete Islands Books, 1980), 270.

7 Ibid., 272 .

8 Ibid 
Photography seems a strange medium, full of "empty spaces," those peculiar cracks and discontinuities between particular images which do not form a coherent narrative. What is more, these "flaws" seem to exist in the photographs themselves. They account for this specific kind of falsification that is a characteristic feature of the medium rather than an intended falsehood. Perhaps it is because of this empty space that photography becomes so easily part of various ideological systems.

John Tagg goes one step further. For him photography cannot be freed from the institutional background in which it is immersed. In The Burden of Representation, Tagg refers to Michel Foucault's concepts to demonstrate that the functioning of photography has been entangled in a complex of industry and ideology. The element of control is said to have appeared already in 19th century photography when a massive expansion of popular amateur photography took place, made possible by the mass production of cameras and photosensitive materials. Photography became easy and commonplace. As techniques of photographic representation developed, they were taken over by public institutions. Tag notes that photographs were used as instruments of administrative and disciplinary authority. ${ }^{9}$ Police, prison and hospital archives were filled with them. Simultaneously, photography came to be understood in the social consciousness as a testimonial to events. The prevalent conviction was that things happened exactly as shown in a photograph. Even propaganda manipulations disclosed every now and then cannot undermine the testimonial value of photography.

Let us now return to Jabłoński's film. The communication between Genewein and the photo company quoted in the film builds the image of a medium used as a propaganda tool. In the Fotoamator documentary, the "correction" of the material from the Ghetto involved putting the photographs in specific context by adding Mostowicz's commentary. In this way, the knowledge of events which was incomplete in view of the visual nature of the testimony became understandable. Photography here was used to some extent as a double agent': testifying to an event, but not forejudging its meaning. What use were Genewein's slides for those who ordered them made? They proved presumably the efficiency of the system. What were they for the photographic company? Perhaps just another step in the testing process of a new technology. What are they for us today? The two previous points of view still count, but today, by proving the rationality of the extermination machinery, the slides testify against their authors.

9 John Tagg, The Burden of Representation. Essays on Photographies and Histories (Minneapolis: University of Minnesota Press, 1999), 20. 


\section{Photography - in Place of the Empty Space}

The example of Jabłonski's film shows the range of issues that are raised when artists undertake to reprocess documentary material. What is more, in many artistic realisations, documentary material juxtaposed with personal or shared memories is an opportunity to deal with a traumatic experience of the past. Commenting on his artistic work in a 1997 interview, Christian Boltański said, "There is a kind of trauma at the beginning of every work." 10 These words take on a singular meaning when applied to photography. In fact, if we were to interpret the "traumatic nature" of photography, it would turn out that the medium is exceptionally suitable to expressing this kind of experience. Let us consider then how to understand "trauma."

In The Return of the Real, Hal Foster refers to Lacan's seminar in which trauma is defined as a missed encounter with the Real." Although the process of losing the Real is irreversible, under special circumstances its return is possible. Foster emphasized that trauma even asks for representation. Here we also find a place for photography, the reproduction-based field of culture. In photography the past returns as a recollection, in the form of an image seemingly repeating what happened in the original experience, but in fact introducing significant changes to this image. Photography repeats, but it "repeats" differently than just imitating reality. Foster calls this process "traumatic realism." The operations involved in photographing - framing, choosing objects, freezing time - transform it irreversibly. In the example that Foster analyzes - Warhol's "reproductionist" works - a similar problem is encountered. Warhol uses photographs from the domain of journalistic or documentary information, retaining their formal attributes: print raster and black and white tones. But his interventions - the magnification and multiplication of the images - restore to the depicted events their original tragic character lost in a mass of similar press news (e.g. Death in America series).

Similar to traumatic experiences, photography is a repression of an event in the consciousness. Transferring an event to photographic paper and creating an archive absolves us from the responsibility of thinking about it. The photographed past disappears from our memory horizon. At the same time, it is saved somehow, even though it is not seen. Photography permits a strange kind of behavior: things we do not want to remember can be put aside "for later" - we can move them away from us. This does not mean, however, that

10 After Mette Sandbye ${ }_{r}$ "Photographic Anamnesis: The Past in the Present, ${ }_{r}$ in Symbolic Imprints: Essays on Photography and Visual Culture, eds. Lars Kiel Bartelsen, Rune Gode and Mette Sandbye, (Aarhus University Press, 1999), 187. 
they will not return. Thus, the point here seems to be the reinstatement of experience, discovering the truth about it.

The Real reveals itself" as if by chance." "Lacan calls this traumatic point touche," writes Hal Foster, and "in Camera Lucida (1980) Barthes calls it punctum."12 It is no coincidence that Foster refers to Barthes' reflection. In Camera Lucida, the perception of photography is almost impossible without relevant individual experience. The social and historical context defines only a general frame for studium. It is punctum bursting through limitations which imbues the picture with meaning. Hit, pierce, wound. These words show that photography can benefit from elements of experience that cannot be expressed rationally. Therefore, it can be a suitable "language" for expressing trauma. Yet, how are we to reconcile this vision of photography with the one presented above, pointing to the institutional involvement of photography? According to Tagg, "neither experience nor reality can be separated from the languages, representations, psychological structures and practices in which they are articulated and which they disrupt."13 However, punctum rests upon just the properties that Tagg mentioned. Indeed, it is as Tagg would have it: punctum may not enrich the cognitive sphere, but the information obtained from studium seems dead as well. In fact, the two positions share the "double agent" function indicated earlier. Photography escapes attempts at unequivocal qualification. It is always suspect, not because what is shown did not happen, but because it can be taken as proof of facts.

Why is it photography that gives us a chance of opening the door leading to the Real? Let it be reiterated: the reality of photography is not about creating an image imitating reality. At least two properties of photography point to the Real: the first one is its indexical character (to use C. S. Pierce's semiotic concept), ${ }^{14}$ and the second is that it lets us see things that belong to the past. In other words, it has that special capability of "haunting" the present. What is characteristic about Peirce's ideas is that none of the elements of the semiotic triangle prevails. Also, indexicality allowing for objective references realizes the link between image and symbol, creating an effective trope in the process of semiosis. Only the linking of the elements creates meanings. Photography, as Walter Benjamin would put it, breaks through the barriers of "optical unconsciousness." "Thanks to it [photography] we became aware of

12 Ibid., 132.

Tagg, The Burden of Representation, 4.

14 Hanna Buczyńska-Garewicz, Semiotyka Piercéa (Warszawa: Biblioteka Myśli Semiotycznej, Polskie Towarzystwo Semiotyczne, 1994); Marianna Michałowska, "Ślad - fotografia i semiotyka," Parergon, $2(2002 / 2003)$. 
optical phenomena, which have been outside our consciousness, just like we come to sublimate subconscious drives through psychoanalysis." ${ }^{5}$ It may be said that it is only trough photography that we become aware of what we see. Photography also serves this function in artistic realisations meant to restore a forgotten past. Let us now take a look at some examples.

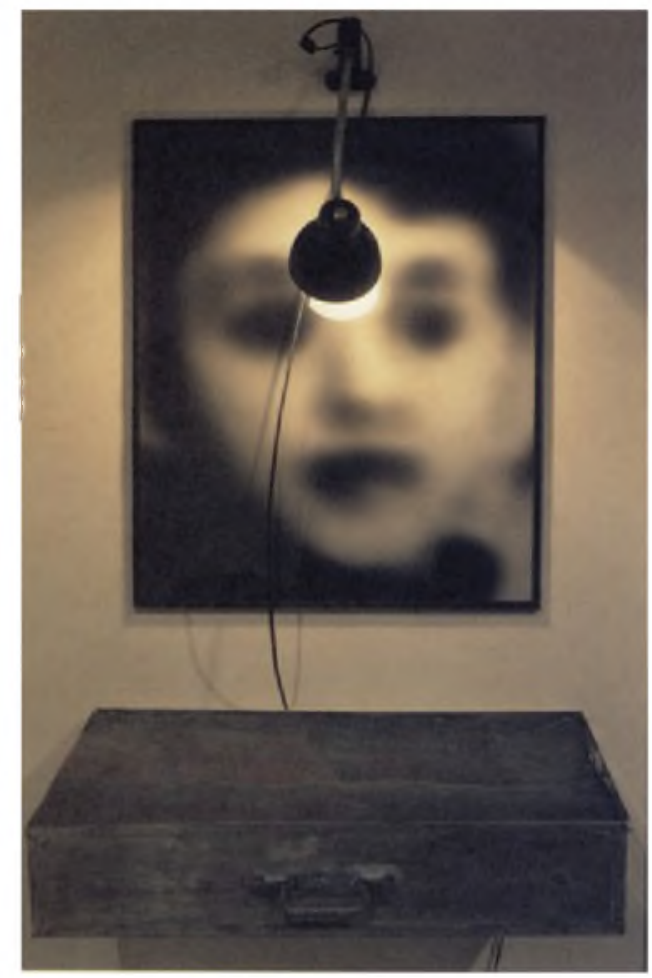

Christian Boltanski, Reserves: La Féte de Pourim, 1989; in Christian Boltanski Inventar (Hamburger Kunsthalle 1991), 2.

In one version of Purim Festival (1990), Christian Boltanski sets up portraits of the dead on a rectangular prism of lead. He illuminates them with small lights attached to the frames. The installation alludes to the motif of the catacombs, as well as that of archives. What could be inside the neatly piled boxes? Human remains? Mementoes? Stories? The author seems to be asking

15 Walter Benjamin, "The Work of Art. In the Age of Mechanical Reproduction," 1936, trans. into Polish by Janusz Sikorski, in Anioł historii. Eseje, szkice, fragmenty, comp. \& trans. Hubert Orłowski (Poznań: Wydawnic two Poznańskie, 1996). 231. 
how, on the day of a festival celebrating the deliverance of the Jews, those who have already departed should be delivered. And by using photographs, he suggested that this can be done through reviving their memory. Boltanski's objects consist of elements taken from archives pieced together in an original way to enable systematic extermination. Once again the ambiguity of archives as an institution is revealed. Established to count, file away and remove the living, the archive now forces us to remember that they had indeed been alive. Despite the underlying intention of erasing a nation from history, the archive extends our memory of this nation. And it does not permit the crime to be forgotten. In Boltanski's huge catalogue, anonymous people do not lose their individuality. At first glance, the same faces seem to be featured in all his installations. But are they really the faces of the same man? The author's strategy is clearly apparent in Gazes. Parts of the faces, the eyes and the root of the nose are shown on successive screens. A comparison of the reproductions reveals minor differences, things that distinguish one reproduction from another, that single out the people in particular pictures. We come to understand the delicate nature of identity. Our illusion of our own individuality virtually disappears. Although facial expression, a smile here, a certain look there, differentiate these characters, it turns out in the end that they are not so different from us. In these portraits, the persons continue to look "as if alive."

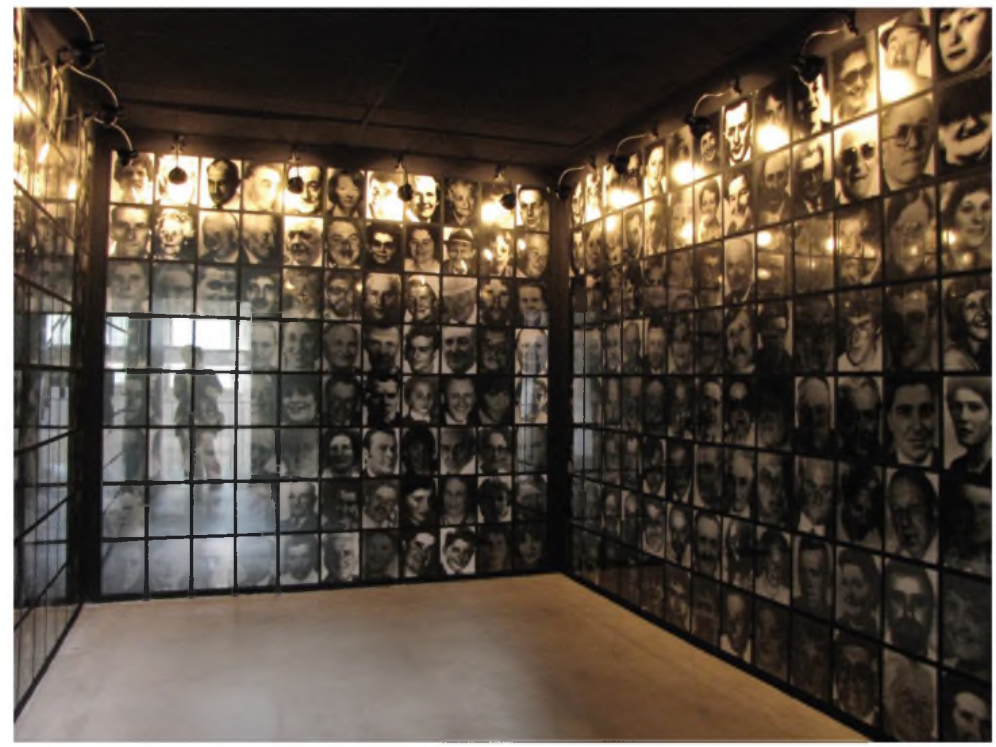

Christian Boltanski, Les Suisses morts, 1990, Collection of Museum für Moderne Kunst, Frankfurt am Main, phot. Marianna Michalowska. 
By means of photography, a medium created to take us into the land of absence, Boltanski exorcises death. If a photographic image is always and exclusively death (as Barthes claimed) and cannot represent anything but the world which no longer exists, then (in keeping with Derrida's perception) a photographic death does not occur only once. ${ }^{16}$ It comes back in more than one form. By recalling strangers, Boltanski evokes at the same time another dimension, another time in our lives. We are filled with the desire to vanquish the ultimate condition; hence the need to restore what is irrevocably gone. We keep photographs to reverse the course of time: on the one hand, to return (revenir) to the past and on the other, to restore the past to the present.

"I got stuck. I cannot get out, I am helpless," wrote Jacques Derrida in Aporias. ${ }^{17}$ An aporia is just the kind of trap a photograph is. Being in the place defined by a photograph, we are unable to decide about either of its sides. We could say the photograph is "this and that," but we could say just as well that it is "not-this and not-that." Derrida's "getting stuck" nicely describes the feeling one gets from looking at Boltanski's works. His creations escape rational evaluation. They are shocking to viewers, but it is difficult to explain exactly why: is it the form or rather the reference to the drastic content? The effect is the result of a collision of the two.

Boltanski draws our attention to the structure of the image, the print raster and the grains of emulsion making it difficult to recognize particular people. This emphasizes the documentary character of the image. The artist is thus referring to an interpretation of the photographic medium that is common to the French tradition. A photograph is close to vera eikon, the real image (it was André Bazin, among others, who wrote that "the Holy Shroud of Turin combines the features of relic and photograph alike"18). And if this is the case, then a photograph must have in itself a "mark" of reality, or to put it differently, an imprinted image of the real event. It is how the work of the French artist is interpreted as a rule. ${ }^{19}$ The objects used in the structures he builds are relics, even though they do not belong to any specific religion. Boltanski refers to the most universal of cults, the cult of

16 Jacques Derrida, "The Deaths of Roland Barthes," in Philosophy and Non-Philosophy since Merleau-Ponty, ed. Hugh Silverman (New York: Routledge, 1998).

Jacques Derrida, Aporias (Stanford: Stanford University Press, 1993), 13.

18 Andre Bazin, "The Ontology of the Photographic Image," trans. Hugh Gray, in Classic Essays on Photography, 244 . 
the dead. The photograph is at once a material object and a mediator with the world of the dead. It may be concluded that the function of photography in his works is to symbolise the ultimate aporia which is death. The events captured in the image are already dead and they come to us from the hereafter in this form.

In the case of Boltanski's oeuvre, the essential thing was the use of images of the absent. It turns out, however, that there are images which we see in places where they no longer exist. This peculiar motif is put to interesting use by a Polish artist living in Berlin. The issue of Shoah representation is not in the mainstream of Roland Schefferski's art, but his works are extremely instructive in relation to the problems discussed here. I will refer here to two of his works: Images Erased From Memory and Create for Yourself Your Own Image of Berlin.

In both cases the artist does a strange thing: he creates pictures, but does not really show them. He cuts the centre out of archival photographs, leaving a kind of passe-partout around an empty space. Just like the fragment of a photograph that has been cut out from the whole, the image is forced out of our consciousness. Cutting out the image also symbolizes the annihilation of some visible part of the past, history which was "bleached." Does the fact, that we do not see the image, mean that it does not exist? Schefferski's work touches upon a very interesting issue - that of history which is full of "blank spots," which is often unwanted. ${ }^{20}$ Historical meaning proves to be changeable and undefined, depending on the context of the times and the "interpreter." In one of his interviews, Peter Greenaway said "there is no history, only historians." This should not be understood as meaning that certain facts can be denied. There are no facts as undeniable as the Shoah. Nevertheless each of us forms a different history based on the same facts. The same happens in Schefferski's works. History is included only potentially for it does not appear until the "reader/viewer" of the picture comes. If we agree with this standpoint, we will see how the documentary force of photography can authenticate many, often contradictory, versions of the same events.

20 Like in the work entitled Proletaryat from the 1998 exhibition Fragmentaryczność pamięci [Fragmentariness of Memory], in which the author cuts the heroes of the communist Poland out of hundred zloty notes withdrawn from circulation. This could be interpreted as the act of a participant in historical events who wants to forget. 


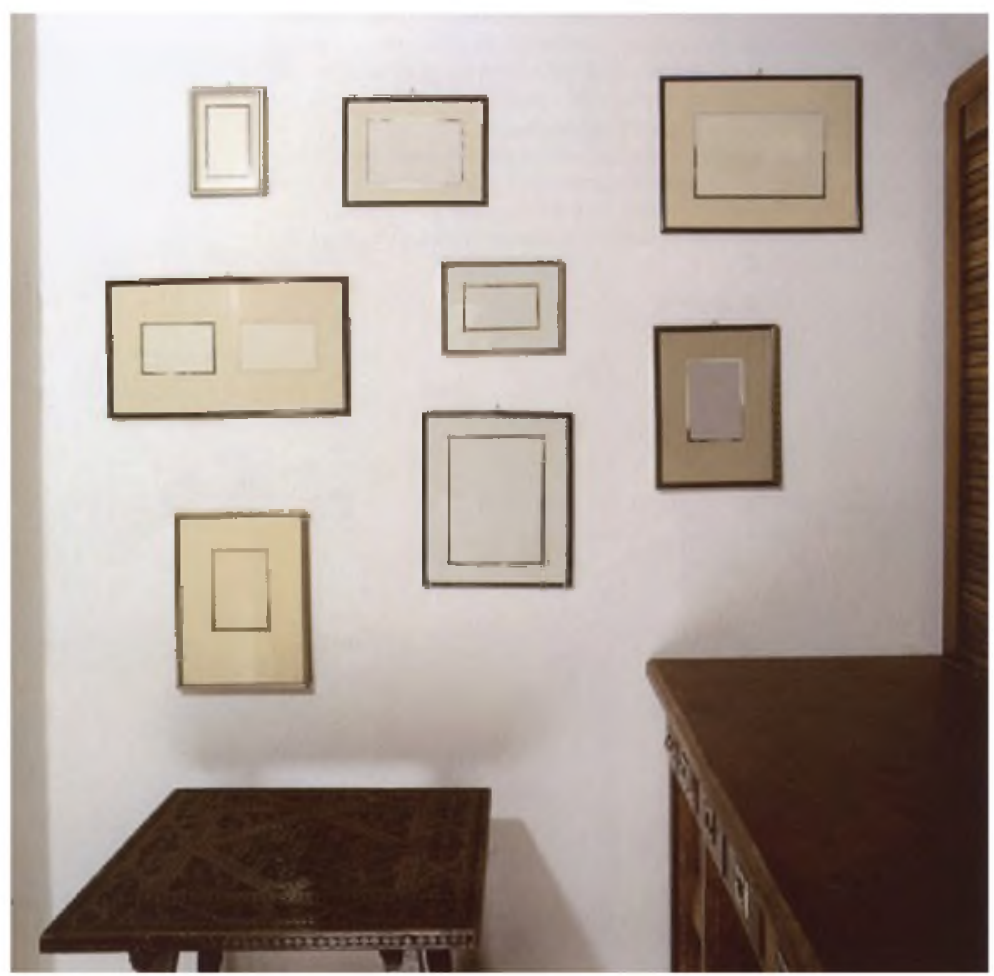

What actually is erasure? A deliberate removal of fragments deemed unwanted - like erasing a sentence written in pencil. Erasure does not happen by itself, like for instance a photographic image which fades under the influence of light. One must want to erase. Cutting out a fragment of a photograph is an equally drastic act. In both cases, however, there is always the chance that a piece will remain (the cut-out part of a photo lost under a cupboard or a letter incompletely obliterated) and become the basis for a reconstruction. Indeed, it is impossible to erase images from memory; all one can do is repress them deeply. Hence, the photograph exists outside its image - in people's memory.

A similar idea to the one employed in Images Erased From Memory gave rise to the Create Yourself Your Own Image of Berlin project. Billboards in Warsaw featured empty picture frames. The task of the viewer was to fill them in "mentally." Paradoxically, however, if we are to fill in the empty space of the frame, we have to reach outside it, to search among other pictures, not the 
ones that are identical to the original (since it has been removed) but among those that are similar. The effect is a peculiar replacement, a reconstruction of the missing image with fragments that have been seen and remembered. We have to remember them. To bring them back from the depths of non-memory.

Let us have a closer look at the cities Schefferski chose for his realisations. Both Gdańsk and Berlin have lost their past - Gdańsk, evacuated and resettled by new people, Berlin, shattered and then put together again. Both cities have been "wounded" by history. And in both places there are continuous attempts made to heal the wounds. The emptiness of the cities refers both to the empty city substance and to the emptiness of its citizens. It demands to be filled. And thus we return to trauma. After all, in Greek the word means a wound.

In the essay on Franz Hessel's Walking in Berlin, Walter Benjamin writes that "a city notebook written by a local person will always be something of a memoir. Not in vain did the author spend his childhood here."21 Can photography act as such a notebook (Benjamin dealt with description exclusively), and be more objective as an image than words? The point is that photography, as stated above, is the basis for a history that is constructed from sights. This is why every family album is different, even when the same city symbols appear in them (the Victory Column on a postcard dating from 1903, for example). ${ }^{22}$ The horse carts featured in the foreground are also not to be found in a contemporary picture of Berlin. Paradoxically, a story is built owing to some missing elements.

Schefferski's empty picture frame is filled with images of the past. The pictures we are dealing with here are ones "taken" by the photographic camera of our mind. The picture stored in memory overlaps a second layer - the image of the city built from knowledge of its culture, a city of architectural signs. The proposal to create one's own image of a city is not merely a nostalgic attempt to return to a lost city from a different time; it is simultaneously a suggestion to build a new city from the broken pieces.

Let us consider the source of images for reprocessing, if what is to be pictured are events in which the artist himself did not participate. In David Levinthal's work the past returns as a simulation. The artist employs miniature figures that are instinctively associated with a child's room. However, it seems more appropriate to see them as objects from an adult's collection. It would be just as difficult to call the depicted situations innocent games (as in the Mein Kampfor Hitler 
Goes East series, for example). The pictures with a deliberately small depth of field depict scenes from World War II: silhouettes of concentration camp guard towers, people leaning over mass graves. Again, these are screens known from documentary or feature films, or from frequently published photographs. They are scenes which already belong to the "optical subconscious," scenes recognized at first glance. Levinthal's photographs are fictions about events that really happened. It is not only "traumatic realism," the desire to express a painful experience, but "traumatic illusionism," meaning the need to repeat what we have not experienced but know only from images. "Here illusionism is employed not to cover up the real with simulacra, but to uncover disquieting things in it."23 In Levinthal's works there is nothing associated with childhood conceived of as a time of peace and security. Childhood is not the age of innocence, since children's games present materials which have not been subject to subsequent memory selection. Fiction and reality can be equally valid for children. It is a time of nightmare and fears. For Boltanski, his childhood is curiously pictured in much the same way. In his 1996 installation entitled Shadows, the shadows of angelic, diabolic and human characters suspended on lines wander across the walls with each blow of the wind.

Brought up in California, David Levinthal acts out the pictures of the Holocaust which reaches him through the media, mostly from pop culture. In Mein Kampf, he uses colour materials. In his meticulously staged projects, however, the reference is not so much to documents as to feature film productions (which is said to be "based on a true story"). Just as in films, we have sophisticated lighting, meticulous framing and depth of fields. The only "interference" in the composition is the subject. After all, his works continue to be a testimony of experience. Not a firsthand experience of the author this time, but one that registers with equal clarity the traces left in him by images of the events.

Let us go back to Benjamin. In his conception, Ryszard Różanowski states that "fully conscious perception becomes an experience owing to the fact that the thing which forms the meaning is finally completed and can now be passed on to "memory administration." 24 In other words, owing to the functioning of consciousness, perception changes into an experience. But what determines experience? According to Benjamin the factor is "involuntary memory." Through "involuntary memory," unconscious meanings are revealed. While it should be remembered that Benjamin did not write about visual experience, it can be assumed that the kind of experience caused by

23 Foster, The Return of the Real, 52.

24 Ryszard Różański, "Walter Benjamin, Marcel Proust i estetyka wspomnienia," Parergon, 2 $(2002 / 2003), 96$. 
photography is close to a direct experience. It is a paradox of sorts that we consider a mediated image authentic. Levinthal's work is about transforming perception into an experience. Images remembered involuntarily (as one cannot escape them living in the world of pop culture) are reworked through staging and they change into a very personal experience of the Holocaust. The "traumatic illusionism" described above is then merely a tool and not the goal of artistic activity. The American's aim is to extract images from the abyss of "involuntary memory" and to subject them to consciousness. Actually, anamnesis, a special area of memory archaeology, works in the same way.

James E. Young writes of a certain attitude according to which there are scenes of the Holocaust that cannot be represented in keeping with ethical principles. "Because no one survived the gas chambers to describe the horror, their darkness has remained absolute." 25 Nonetheless, many attempt such representations. Perhaps because it is an unimaginable reality. Representation of the Holocaust is in artistic practice an ambiguous issue because it seems impossible to be expressed. At the same time there should not be silence about the Shoah. In Levinthal's works, the replaying of child's games does not serve the purpose of taming a traumatic experience - trauma is not tamable. But the experience, as stated by Foster, calls for replaying and Levinthal submits himself to this internal call.

In the works of Boltanski, Schefferski and Levinthal, the focus is on juxtaposing the present and the past. The past haunts the present in the form of remembered scraps of history. It is impossible to reconstruct them absolutely, from documents and traces. But these documents and traces cannot be read unambiguously. They keep returning in new configurations. The nature of photographic documents makes us think of it in similar fashion. "As an image type, the photography is both banal and fraught with meaning but difficult to penetrate (like trauma)," writes Mette Sandbye. ${ }^{26}$ The reasons is that a photograph is situated between the strictly subjective (as a sign ready to be filled by the reader) and objective (since it has historical references in the past). This must be why John Tagg searched for the justification of photography outside the medium, in the commentary of ideologies, in the functioning of public institutions. It is why it is so easy to observe "falsification" in photography. At the same time, however, this duality lets artists exceed the limitations of the document and enables reality to appear between the grains of emulsion.

\section{Translation: Tomasz Niedźwiedź}

25 James E. Young, AtMemory's Edge. After-Images of the Holocaust in Contemporary Art and Architecture, (Yale: Yale University Press 2000), 55

26 Sandbye ${ }_{t \prime}$ Photographic Anamnesis, " 181. 